\title{
Heterogeneity of osteogenesis imperfecta type I
}

\author{
C R PATERSON, SUSAN MCALliON, AND RUTH MILlER \\ From the Departments of Biochemical Medicine and Community and Occupational Medicine, \\ University of Dundee, Dundee DD1 $4 H N$.
}

SUMMARY We have studied 166 patients from 71 families with Sillence type I osteogenesis imperfecta (dominant inheritance and blue sclerae). We confirm earlier findings that there are two subgroups, those with and those without dentinogenesis imperfecta; each family can be allocated to one or other group. Our confidence that the two groups represent distinct disorders is increased by finding that the patients with dentinogenesis imperfecta differ not only in their dental characteristics but also in other clinical features. They have a more severe disease with a greater fracture rate and a greater likelihood of growth impairment.

It has long been recognised that substantial variations can be found among patients with osteogenesis imperfecta (OI). Patients differ not only in the natural history of the condition, but also in features such as growth impairment, skull shape, scleral colour, dental abnormality, and joint hyperextensibility. Radiologically the bones may be apparently normal or grossly abnormal. Genetic studies have shown that both dominant and recessive variants exist.

Consideration of all these forms of variation led Sillence and his colleagues ${ }^{1}$ to propose a classification in which there were two dominant varieties and two recessive varieties of OI. The two dominant varieties could be separated according to whether the sclerae were blue or not. The group with dominant inheritance and white sclerae (type IV) was small compared with that with blue sclerae (type I).

Subsequently Levin et $a l^{2}$ showed that patients with dominantly inherited OI could also be separated into two groups according to whether or not dentinogenesis imperfecta (DI) was present. In five families all the members whose teeth were examined had opalescent teeth with typical radiological and scanning electron microscope appearances. In two families the teeth of all the members were normal. The teeth of 25 patients were studied; these included both those with and those without blue sclerae.

This paper describes an attempt to determine whether the findings of Levin $e t a l^{2}$ were valid in a large group of patients limited to a single variety of dominant OI as defined in the Sillence classification.

Received for publication 30 September 1982. Accepted for publication 11 November 1982.

\section{Methods}

Information on 166 patients from 71 families with dominantly inherited OI with blue sclerae was entered on a standard questionnaire designed for computer processing. Of these subjects, 106 were seen personally by CRP; the remaining questionnaires were completed by the patients, their parents, or by occupational therapists visiting on behalf of the Brittle Bone Society. In the case of patients seen personally or by the occupational therapists, particular note was made of the height (or length), the shape of the skull, and the presence or absence of dentinogenesis imperfecta.

\section{Results}

It proved possible to allocate each family either to a group without dentinogenesis imperfecta (OI type IA) or to a group with DI (OI type IB). In all there were 137 type IA patients in 58 families and 29 type IB patients in 13 families. Two patients in type IB families had apparently normal teeth. Three patients in type IA families had discoloured teeth. In one case the patient had been treated with tetracycline in early childhood and in the other two there was no obvious explanation. None of these five cases was seen personally. In all those who were examined there was a clear concordance in respect to DI within each family.

After the families had been divided as described, the clinical features in each group were examined. The fracture rate was significantly higher in type IB than in type IA between the ages of 5 and 20 (fig 1). 


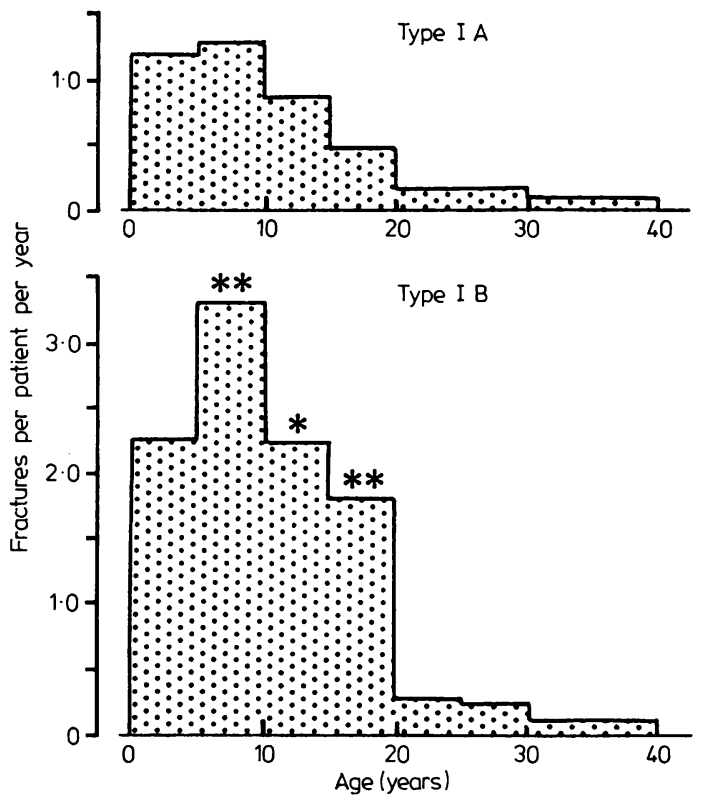

FIG 1 Mean numbers of fractures in each 5-year period (excluding any fractures identified at birth) in patients with type I OI without (type IA) or with (type IB) dentinogenesis imperfecta. The differences between the two groups were examined by Student's $t$ test. ${ }^{*} p<0.05,{ }^{* *} p<0.01$.

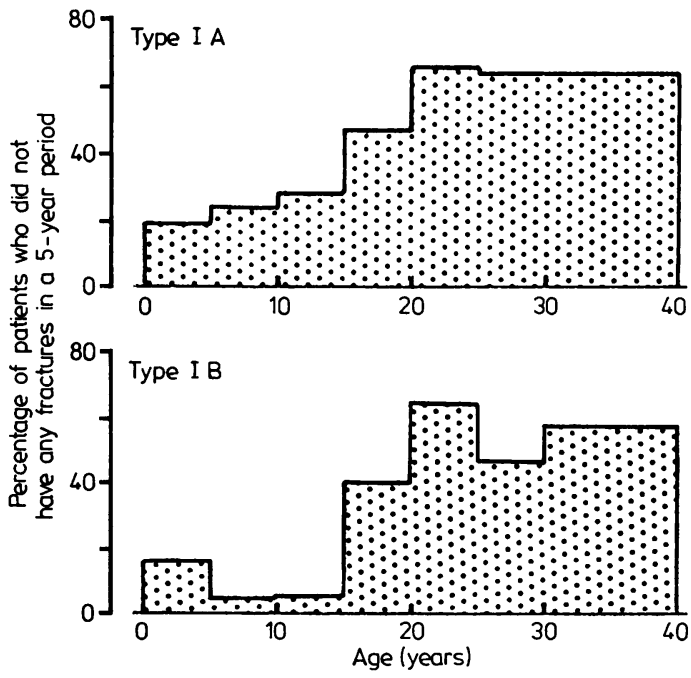

FIG 2 Proportion of patients having completely fracturefree 5-year periods in those without (type IA) and with (type IB) dentinogenesis imperfecta. The two groups were significantly different $(p<0.025)$ by the Mantel-Haenszel Test. ${ }^{\mathrm{3}}$
T ABLE Clinical features of patients with dominant $O I$ without dentinogenesis imperfecta (type IA) and with dentinogenesis imperfecta (type IB).

\begin{tabular}{|c|c|c|c|}
\hline & $\begin{array}{l}\text { Type IA } \\
\% \\
\text { affected }\end{array}$ & $\begin{array}{l}\text { Type IB } \\
\% \\
\text { affected }\end{array}$ & $p$ \\
\hline $\begin{array}{l}\text { First fracture at birth } \\
\text { Hyperextensible joints } \\
\text { Bruising } \\
\text { Nosebleeds } \\
\text { Deafness (among patients aged over 40) } \\
\text { Skull fracture } \\
\text { Rib fractures } \\
\text { Dislocated joints } \\
\text { Excessive sweating } \\
\text { Height less than 2 SD } \\
\text { Height less than } 4 \text { SD }\end{array}$ & $\begin{array}{r}6 \cdot 1 \\
43 \cdot 8 \\
78 \cdot 8 \\
24 \cdot 8 \\
55 \cdot 2 \\
6 \cdot 6 \\
31 \cdot 4 \\
28 \cdot 7 \\
37 \cdot 9 \\
24 \cdot 8 \\
5 \cdot 8\end{array}$ & $\begin{array}{l}25 \cdot 0 \\
62 \cdot 1 \\
89 \cdot 6 \\
31 \cdot 0 \\
71 \cdot 4 \\
17 \cdot 2 \\
20 \cdot 7 \\
34 \cdot 5 \\
60 \cdot 7 \\
59 \cdot 3 \\
25 \cdot 9\end{array}$ & $\begin{array}{l}<0.005 \\
\text { NS } \\
\text { NS } \\
\text { NS } \\
\text { NS } \\
\text { NS } \\
\text { NS } \\
\text { NS } \\
<0.05 \\
<0.005 \\
<0.005\end{array}$ \\
\hline
\end{tabular}

p was determined with the $\chi^{2}$ test with Yates's correction.

NS = no significant difference.

Fig 2 demonstrates the greater severity of the $\mathrm{OI}$ in type IB patients in a different way; a significantly greater proportion of the type IA patients than the type IB patients had prolonged fracture-free periods in childhood. The table compares the other clinical features in the two groups. It can be seen that patients in the families with DI were significantly more likely to have had a fracture at the time of birth, to have impairment of growth, and to have excessive sweating as an associated symptom.

\section{Discussion}

Among patients with type I osteogenesis imperfecta two subgroups can be recognised: those with and those without dentinogenesis imperfecta. With only five apparent exceptions in 166 patients each family was consistent in whether or not members with OI also had DI. It is likely that had the teeth of these five patients been examined clinically or, better still, radiologically, the concordance would be complete. Our conclusions are therefore similar to those of Levin $e t$ al. $^{2}$ The present study provides additional evidence that the two subgroups of OI type I are distinct. The patients in the two groups differ not only in their dental findings but also in other clinical features. In particular the fracture rate was significantly higher in the patients with abnormal teeth and the incidence of growth impairment was much higher in the same patients.

There is growing evidence that most or all forms of OI are caused by molecular abnormalities in the structure or post-translational modification of collagen..$^{4-8}$ Since dominantly inherited OI is clearly heterogeneous it is likely that the different clinical variants identified have different underlying causes in molecular terms. 
We are indebted to the Brittle Bone Society, the Rehabilitation and Medical Research Trust, and the Children's Research Fund for financial support, to Miss Alison Wisbeach and Mrs Lorraine Clarke for completing some of the questionnaires, to Mrs $\mathbf{M}$ Geekie for excellent secretarial help, to Professor G $\mathbf{H}$ Bell for comments on the manuscript, and to Mr S A Ogston for advice on statistics.

\section{References}

1 Sillence DO, Senn A, Danks DM. Genetic heterogeneity in osteogenesis imperfecta. J Med Genet 1979;16:101-16.

2 Levin LS, Brady JM, Melnick M. Scanning electron microscopy of teeth in dominant osteogenesis imperfecta. Am J Med Genet 1980;5:189-99.

3 Mantel N, Haenszel W. Statistical aspects of analysis of data from retrospective aspects of disease. $J$ Natl Cancer Inst 1959;22:719-48.

4 Peltonen L, Palotie A, Prockop DJ. A defect in the structure of type I procollagen in a patient who had osteogenesis imperfecta: excess mannose in the COOHterminal propeptide. Proc Natl Acad Sci USA 1980;77: 6179-83.

5 Pope FM, Nicholls AC, Eggleton C, Narcissi P, Hey EN, Parkin JM. Osteogenesis imperfecta (lethal) bones contain types III and V collagens. J Clin Pathol 1980; 33: 534-8.

6 Francis MJO, Williams KJ, Sykes BC, Smith R. The relative amounts of collagen chains $\alpha 1(\mathrm{I}), \alpha 2$ and $\alpha 1$ (III) in the skin of 31 patients with osteogenesis imperfecta. Clin Sci 1981;60:617-23.

7 Krieg T, Kirsch E, Matzen K, Muller PK. Osteogenesis imperfecta: biochemical and clinical evaluation of 13 cases. Klin Wochenschr 1981;59:91-3.

8 Barsh GS, David KE, Byers PH. Type I osteogenesis imperfecta: a non-functional allele for pro $\alpha 1(\mathrm{I})$ chains of type I procollagen. Proc Natl Acad Sci USA 1982;79: $3838-42$.

Correspondence and requests for reprints to Dr C R Paterson, Department of Biochemical Medicine, Ninewells Hospital, Dundee DD1 9SY, Scotland. 